\title{
Attributes That Determine the Building Information Modelling Capability Maturity of Quantity Surveying Practice
}

\author{
Abdul-Majeed $\mathrm{M}_{\text {ahamadu }}{ }^{1}{ }^{*}$, Lamine $\mathrm{M}$ ahdjoubi ${ }^{1}$, Patrick $\mathrm{M}$ anu ${ }^{2}$, and Clinton Aigbavboa ${ }^{3}$ \\ ${ }^{1}$ U niversity of the W est of England, F renchay Campus, B ristol, BS16 1QY, U nited K ingdom \\ ${ }^{2} U$ niversity of $M$ anchester, The School of M echanical, A erospace \& Civil Engineering, M anchester \\ M 13 9PL, U nited Kingdom \\ ${ }^{3}$ University of J ohannesburg, The Faculty of Engineering and the B uilt Environment, J ohannesburg, \\ South A frica
}

\begin{abstract}
With more than $80 \%$ of all construction projects overrunning their budget, there is a need for more efficient management of the estimated $10 \%$ of Gross Domestic Product (GDP) that is expended annually on construction across the world. It has been proposed that better information and data management through Building Information M odelling (BIM ) will lead to cost savings and greater predictability. Notwithstanding the role of quantity surveyors (QS) in modelling and managing construction cost, they remain among the least capable of assimilating BIM into their existing traditional processes. Despite the increasing need for BIM capability assessments for projects, there remains, no tool specifically developed for assessing QS firm's BIM utilisation capacity or performance. As a result, it is unclear the attributes that indicate BIM capability of QS firms as well as QS practices on projects. This study sought to address this through a review of BIM capability assessment frameworks in order to ascertain their suitability for QS practices. An expert focus group discussion was then used to identify peculiar attributes suitable for QS BIM capability assessment as a precursor to the development of a comprehensive model of QS BIM capability maturity. Findings reveal that most QS BIM capability attributes relate to processes including criteria for effective information definition and data management such that they are consistent with QS measurement standards. The BIM competence of staff also emerged as one of the key attributes highlighting the need for QSs to improve their knowledge, skills and experience in the application of BIM amidst current low levels of adoption. The proposed attributes would assist the devel opment of performance and maturity indicators that would help QS firms better understand their own capability as well as the requirements for delivering costing services through BIM on projects.
\end{abstract}

Keywords: costing, information modelling, quantity surveying, projects, competence, maturity

\footnotetext{
${ }^{*}$ Corresponding author: abdul.mahamadu@uwe.ac.uk
} 


\section{Introduction}

The majority (circa $80 \%$ ) of construction projects overrun their budget $[1,2]$, thereby making it imperative for more efficient management of financial resources expended annually for the delivery of construction. Global initiatives on IT adoption for construction envisage significant cost savings from the implementation of novel digitally driven processes. For instance in the UK Government hopes to achieve up to $33 \%$ cost savings through the digitisation of processes with Building Information Modelling (BIM) [3]. Notwithstanding the role of Quantity Surveyors (QS) in modelling and managing construction cost, they remain among the least capable of assimilating BIM into their existing traditional processes: only a meagre $10 \%$ of the mostly SME QS firms are reported to be using digitised BIM-based practices[4]. Despite the increasing need for BIM capability assessments for projects, there remains, no tool specifically developed for assessing QS firm's BIM utilisation capacity or performance. Emerging tools and frameworks have been designed for organisations with high design responsibility (such as architects) rather than for QS who directly manage and control spending on projects [5-12].

The aim of this study is, therefore, to develop a BIM capability assessment framework specifically for QS BIM utilisation, benchmarking and performance. This will aid the development of a set of metrics for evaluating the ability of QSs to deliver services through BIM as well as serve as an evaluation tool to aid alignment of QS BIM implementation with performance expectations. In this article, the attributes that determine a QS organisation's BIM capability is explored as a precursor for the development of a comprehensive capability maturity model.

\section{Quantity Surveying Practice and the Use of BIM and Related Technologies}

The major role of QSs in construction projects is costing and managing cost-related activities, this requires expertise in the measurement of quantities of building elements with procedures such as quantity take-off (QTO), cost modelling as well as other contract administration and commercial management functions. The traditional approaches to QS rely on traditional paper-based tools $[13,14]$. The potential of BIM to create efficient working approach among construction professionals has however been proven by the wide adoption of 3D BIM by architects and engineers in optimising design visualization and evaluation of design choices [15]. Building contractors have also adopted 4D BIM for construction planning and scheduling but the adoption of 5D (use of BIM for costing and commercial applications) is relatively low [4]. According to Ustinovičius et al. [16], 5D BIM is a critical element of building lifecycle management through precise cost estimation as well as the elimination of human-related errors. Furthermore, Reizgevicius et al. [17] have highlighted the importance of QS practices such as life cycle costing and reliable cost analysis of different construction scenarios in the attainment of sustainability through BIM use.

The Industry Foundation Classes (IFC) has increased the opportunities for QSs to collaborate with all other industry professionals through the facilitation of open data formats for the transfer of information across various applications [4]. BIM offers a faster and effective approach to generate relevant data for QS functions in order to develop cost estimates through automated extraction of quantities from building models, it also enables parametric links for automatic updates of quantities when design changes occur [18]. The efficiency of delivering cost-effective projects has been greatly influenced by innovative technology thus critical processes such as cost planning, cost control, cost estimating and analysis can now be achieved more effectively using BIM application and platforms (i.e. 5D BIM) [4, 14]. There are more opportunities offered by innovative technology towards 
improving the efficiency of project costing and QS practice overall. Most QS functions can, therefore, be more easily achieved with the application of digital technology and data analytics $[4,15]$.

Ashworth and Hogg [19] predicted the expansion of QS practices to cover automated measurement, environmental and sustainability analysis, facilities management, legal services, investment advice and quality management through the adoption of digital technology. Although there is a perceived threat to the QS profession with the prospect of replacing people with technology, the opportunities ahead are more than the threats [15]. Aside from the expanding opportunities in the scope of QS practice, there is an important role for QSs in the BIM development market. The skills required to drive such 5D BIM is however enormous and QS practice requires some capacity building [14, 20].

\section{Organisational Capability and the Implementation of BIM}

Capability Maturity Models (CMM) have been adopted for the assessment of the quality of organisational processes within software firms since the late 1970s [21]. Some of the most popular models include the quality management maturity grid by Crosby [22] and the CMM by Carnegie Mellon Software Engineering Institute (SEI) [21]. According to Eadie et al. [23], maturity models are characterised by structured elements representing key process areas as well as capability stages for progressing in these process areas. Thus, a maturity model aids the identification of critical process areas responsible for a firm's performance or capability in delivering a particular function [22]. They are popularly used in performance management to provide guidance on steps towards improving performance in key organisational process areas. Similarly, with the emergence of BIM, the maturity modelling concept has been adopted to model BIM capability [7, 12, 24]. Succar et al. [25] defined BIM maturity as "the quality, repeatability and degree of excellence within a BIM capability". According to Succar [24], BIM maturity is primarily used to benchmark performance improvement milestones during BIM implementation or use. The notable BIM capability maturity frameworks and toolsets include the Capability Maturity Model (CMM) by the National Institute of Building Science [7]; the Indiana University BIM proficiency matrix [26]; the BIM capability framework by Succar [24]; the BIM owners' competency framework by Giel and Issa [12]; the BIM Quickscan [6]; the BIM readiness frameworks by Gu and London [27]; BIM pre-qualification and selection framework [28] and ARUP's project maturity assessor [29]. The major limitation of these frameworks relative to QSs is, however, the fact that none of them has been specifically developed for QSs. Some generically apply to construction organisations $[7,8,24,28]$ while others apply to project scenarios [26, 29]. Giel and Issa's [12] model focussed on clients while all of the other frameworks do not specifically target particular disciplines however most suited for originations with design responsibility [28]. Some other frameworks have been developed for the assessment of the product (i.e. BIM model) maturity [11].

While these emerging standards, frameworks and tools have provided the basis for the identification of appropriate BIM capability criteria, none of them specifically address peculiar needs of QSs and QS practices. The only model with criteria for assessment costrelated BIM modelling process is the ARUP model [29]. However, this model pertains to BIM model maturity for projects rather than a QS organisation's maturity. Furthermore, it relies on a generic set of criteria that are used for assessing other disciplines such as Architecture, Mechanical and Electrical, thus, the criteria are not specific to QS. From the review of the state-of-the-art, it is clear that no BIM capability assessment tool exists for QSs, neither is it clear if the generic capability attributes proposed in existing frameworks are suitable for QS processes and organisations. 


\section{The Identification of Key Attributes for a BIM Capability Maturity Model for Quantity Surveying}

The development of capability maturity models requires the identification of key attributes often referred to as key process areas (KPA) which represent the primary areas of performance in an organisation or system [5, 21, 23]. These capability attributes (KPA's) are distinct clusters of related activities, competencies and resources that are required for the attainment of goals [21]. The conventional notion of KPAs is that they must include processes, people and personnel, policy, systems and resources required to perform functions effectively and efficiently [24, 28]. This study, therefore, explored the attributes required for assessing a QS organisation's capability to deliver BIM as a precursor for developing a comprehensive capability and performance benchmarking framework based on capability maturity modelling principles.

\section{Methodology}

A focus group discussion (FGD) involving experts in the application of BIM for QS was used to identify a list of attributes that denote QS organisations ability to use BIM. This process allowed experts to propose criteria as well as review generic criteria derived from a review of the literature and existing BIM capability frameworks. The FGD further aided the exploration of expert views on the potential of BIM for transforming QS practices as well as review the current capacity and capability issues in the industry. A total of seven experts were engaged in the FGD. The FGD participants comprised mainly of QSs, BIM Managers, BIM Consultants and a QS software developer. All participants had a vast experience in the application of digital technologies for construction as well as QS practice in general. They were recruited from reputable organisations with departments or projects responsible for the digitisation of QS functions. High level of expertise was a criterion for selecting participants and was also in order to meet the requirements for selecting participants when using expert group methods for data collection [30]. The following criteria were specifically relied on in selecting participants: senior professional or academic in BIM and QS; a minimum of five years of industry experience; and possession of professional QS or BIM qualifications. The background information of FGD participants is presented in Table 1. FGDs normally involves a small group of participants to ensure effective management of the data collection by the researchers [31]. Focus group methods are the preferred approach for interrogation of the phenomenon to high levels of detail and depth while reducing interviewer-domination $[31,32]$. FDGs have been previously used for the identification of capability attributes in the development of capability maturity models [33]. The FGD was adopted to allow the participants to draw from each other's expertise and experience regarding QS BIM capability in order to enrichen the discussions.

Table 1. Background of FGD Participants.

\begin{tabular}{ccccc}
\hline ID & Role/Position & $\begin{array}{c}\text { Experience } \\
\text { in } \\
\text { Construction }\end{array}$ & $\begin{array}{c}\text { Experience in } \\
\text { Digital } \\
\text { Construction }\end{array}$ & Qualification \\
\hline 1 & BIM Manager & 20 & 7 & $\mathrm{BSc}$ \\
\hline 2 & $\begin{array}{c}\text { Director - QS Software } \\
\text { Development (*MICE) }\end{array}$ & 40 & 12 & $\mathrm{BSc}$ \\
\hline 3 & $\begin{array}{c}\text { Associate Director - QS and } \\
\text { Commercial Management (*MRICS) }\end{array}$ & 15 & 5 & $\mathrm{BSc}$ \\
\hline 4 & Construction Manager & 10 & 2 & $\mathrm{MSc}$ \\
\hline 5 & Digital Construction Consultant & 16 & 15 & $\mathrm{BSc}$ \\
\hline
\end{tabular}




\begin{tabular}{ccccc}
\hline 6 & $\begin{array}{c}\text { Associate Director - QS and } \\
\text { Commercial Management (*MRICS) }\end{array}$ & 14 & 3 & BSc \\
\hline 7 & $\begin{array}{c}\text { Academic and Professional QS } \\
(* \text { MRICS) }\end{array}$ & 30 & 10 & MSc \\
\hline $\begin{array}{l}\text { *Notes: BSc = Bachelors Degree; M Sc = M asters Degree; M RICS = M ember, Royal Institution of Chartered Surveyors; M MICE = } \\
\text { Member, Institution of Civil Engineering }\end{array}$ & & \\
\hline
\end{tabular}

\section{Findings and Discussions}

The QS BIM capability attributes derived from the FGD is presented in Table 2. In total 18 key capability attributes were proposed. Some of the attributes proposed are similar to proposed attributes in BIM capability and maturity frameworks but uniquely differ given its focus on the QS practice. The criteria that are similar to previously proposed BIM capability are: Staff competence; Organisations experience; Organisation's qualifications; Hardware; Software; Network capacity; Leadership; Policy; and Roles and responsibilities $[10,24,28]$. The criteria peculiar to QS BIM use include: Scope of QS services rendered digitally; Commercial and cost data security; Commercial data security; Cost model progression specification; Cost data exchange protocols; and 5D BIM execution planning.

Table 2. Summary of Quantity Surveying BIM capability attributes.

\begin{tabular}{|c|c|c|c|c|c|}
\hline \multirow[b]{2}{*}{ No. } & \multirow[b]{2}{*}{ QS BIM Capability Attributes } & \multicolumn{4}{|c|}{$\begin{array}{c}\text { Key process area (KPA) } \\
\text { category }\end{array}$} \\
\hline & & $\frac{0}{\stackrel{\Xi}{\circ}}$ & 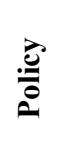 & 苞 & 峁 \\
\hline 1 & $\begin{array}{c}\text { Staff Competence } \\
\text { Skills, knowledge, experience and expertise among staff. } \\
\text { Professional and academic qualifications relevant to 5D } \\
\text { BIM and digital technology application. } \\
\end{array}$ & $\mathrm{X}$ & & & \\
\hline 2 & $\begin{array}{c}\text { Organisations experience } \\
\text { Historical/previous use of 5D BIM and digital } \\
\text { technologies within the organisation and on projects. }\end{array}$ & $\mathrm{X}$ & & & \\
\hline 3 & $\begin{array}{l}\text { Organisations qualifications and certification } \\
\text { Formal certifications indicating BIM capability, maturity, } \\
\text { competence, standards and use of protocols. }\end{array}$ & $\mathrm{X}$ & & & $\mathrm{X}$ \\
\hline 4 & $\begin{array}{c}\text { Scope of QS services rendered digitally } \\
\text { Delivery of core costing and QS functions through BIM, } \\
\text { advanced digital technologies and data analytics. }\end{array}$ & & & & $\mathrm{X}$ \\
\hline 5 & $\begin{array}{c}\text { Hardware } \\
\begin{array}{c}\text { Hardware to support 5D BIM, data capture, storage, } \\
\text { analytics and advanced visualisation. }\end{array}\end{array}$ & & & $\mathrm{X}$ & \\
\hline 6 & $\begin{array}{c}\text { Software } \\
\text { Software to support 5D BIM, data capture, storage, } \\
\text { analytics and advanced visualisation. }\end{array}$ & & & $\mathrm{X}$ & \\
\hline 7 & $\begin{array}{l}\text { Network capacity } \\
\text { Adequate and secure network infrastructure to support 5D } \\
\text { BIM through centralised or cloud-based interoperable data } \\
\text { exchange. }\end{array}$ & & & $\mathrm{X}$ & \\
\hline 8 & $\begin{array}{l}\text { Workflow management } \\
\text { Process maturity within the organisation for object-based, } \\
\text { model-based or network-based integration of cost services } \\
\text { into BIM (5D). }\end{array}$ & & & & $\mathrm{X}$ \\
\hline
\end{tabular}




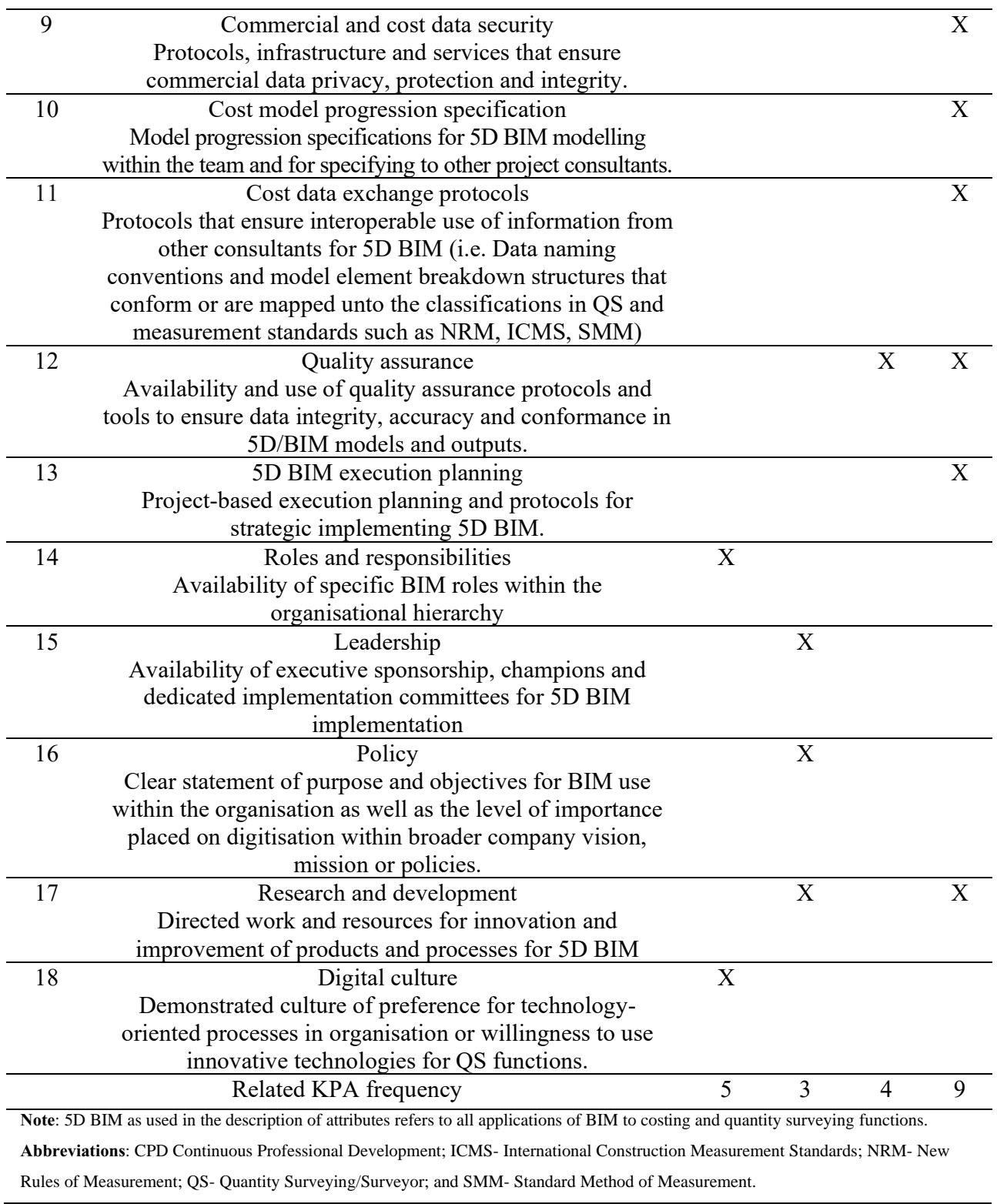

Based on the categorisation of BIM maturity elements by Succar et al. [25], the attributes were reclassified into four distinct categories. The classification of attributes was as follows: technology, process, people and policy. The technology category describes specific abilities related to physical artefacts including software, hardware and data or networks. The process category is used to describe activities, workflows, services, procedures for delivering BIM. The people category describes knowledge skills and competence possessed within an organisation or by individuals for the delivery of BIM objectives. Finally, the policy dimension describes the guidance and principles of action adopted for the attainment of BIM implementation goals.

The majority of attributes $(n=9)$ were 'process' related though unsurprising and supports the primary definition of BIM which emphasizes its process laden nature [5]. Capability maturity models are also premised on a philosophy that process improvement is responsible 
for the attainment of objectives in digital technology use [21]. A significant amount of the process criteria were related to the management of information and data exchange. This finding brings into focus the role of interoperability in the effective delivery of QS functions through BIM [4]. While the IFC has increased the opportunities for QSs to collaborate with other disciplines, there remains a need for protocols to facilitate the process and organisational interoperability [4]. The attributes proposed thus highlight the need for capacities in the definition and classification of data such that they are consistent with QS and measurement standards such as Standard Method of Measurement (SMM), International Construction Measurement Standards (ICMS) and the New Rules of Measurement (NRM). The majority of proposed QS BIM capability attributes align with a systems and hard technology deterministic view of BIM capability [28]. The category with the second-highest number of attributes $(n=5)$ was the 'people' category with emphasis on competence and experience of individuals and the organisation as a whole in delivering QS related services through BIM. According to Succar et al. [9], the ability to adopt BIM-related processes is dependent on proficiency among staff, as well as its aggregated effect on the entire organisation through collective learning as well as the distribution of roles and responsibilities. Existing BIM frameworks and toolsets [5, 6, 8-10, 12] have similarly recognised people-centric competency measures as influential determinants of BIM capability. The concern is, however, the low level of QS BIM adoption which will invariably delay the process of developing a critical mass of QSs experienced in the use of BIM-related process and technology.

The findings reveal critical QS BIM capability attributes as well as dominant categories of attributes. The dominance of particular types of the QS BIM capability attributes does not, however, indicate their importance thus there is a need for further research to determine the relative importance of criteria.

\section{Conclusion}

The use of BIM within QS practice is becoming more necessary as a result of high levels of BIM use and diffusion across other segments of the construction industry. Despite the potential of BIM, however, QSs continue to lag behind in adoption as a result of capability issues among other reasons. A review of studies reveals that the majority of emerging tools and frameworks have been developed for organisations with high design responsibility (such as architects) rather than for QSs who directly manage and control spending on projects. Consequently, there are serious limitations regarding the suitability of criteria in existing BIM capability and maturity frameworks for use in QS scenarios. This study thus sought to address this by proposing QS specific BIM capability attributes. Findings reveal that most QS BIM capability relates to 'process' including criteria for effective information definition and data management such that they are consistent with QS and measurement standards. The proposed QS BIM capability attributes highlight the key process areas for the development of performance and maturity indicators that would assist QS firms to better understand capability issues as well as BIM implementation priorities. A limitation of this study is the lack of prioritisation of attributes to determine which is the most important. The subsequent phase of this study will, however, address this and prioritise these attributes as well as identify definitions of maturity levels for each. This study relied only on expert judgement, thus future studies could adopt longitudinal, ethnographic approach or case studies to explore further, the attributes identified in the current study as well their relative importance in practice. 


\section{References}

1. B. Flyvbjerg, M.K.S. Holm S.L. Buhl, W hat Causes Cost O verrun in Transport Infrastructure Projects? Transp. Rev. 24(1), 3-18 (2004)

2. D.D. A hiaga-Dagbui, S.D. Smith, Rethinking construction cost overruns: cognition, learning and estimation J FM PC 19(1), 38-54 (2014)

3. BIS, Industrial Strategy: Government and Industry in Partnership: Construction 2025, Report number: URN BIS/13/955 (Department for Business, Innovation and Skills, London, 2013)

4. RICS, Can Building Information M odelling (BIM) Support the N ew Rules Of M easurement (NRM 1) (R oyal Institution of Chartered Surveyors (RICS), L ondon, 2014)

5. B. Succar, B uilding Information M odelling Framework: A Research and Delivery Foundation for Industry Stakeholders. A utomat. Constr. 18(3), 357-375 (2009)

6. L. van B erlo, T. Dikkmans, H. Hendriks, D. Spekkink, W. Pel, Benchmark of BIM Performance in the Netherlands, in Proceedings 29th International Conference CIB W 78 2012, 17-19 October 2012, B eirut, Lebanon (2012)

7. NIBS, National Building Information M odeling Standard - V ersion 2.0-Chapter 5.2 Minimum BIM (2012)

8. CIC - Computer Integrated Construction, BIM Planning Guide for Facility Owners: Computer Integrated Construction (Pennsylvania State University, Pennsylvania, 2013)

9. B. Succar, W. Sher, A. Williams, An Integrated A pproach to BIM Competency A ssessment, A cquisition and A pplication, A utomat. Constr. 35, 174-189 (2013)

10. C. K am, D. Senaratna, B. M CK inney, Y . Xiao, M. Song, The V DC Scorecard: Formulation and $V$ alidation. Stanford U niversity: Center for Integrated Facility Engineering (CIFE), CIFE W orking Paper W P135 (2014)

11. J. Du, R. Liu, R. Issa, BIM Cloud Score: Benchmarking BIM Performance, J. Constr. Eng. M anag. 140(11), 04014054-64 (2014)

12. B. Giel, R. Issa Framework for Evaluating the BIM Competencies of Building Owners, Comp. Civ. Build. Eng., A SCE, 552-559 (2014)

13. D. M itchell, 5D BIM: Creating cost certainty and better buildings (RICS Cobra, LaS V egas, Nevada, 2012)

14. N.A.A. Ismail, R. Drogemuller, S. B eazley, R. Owen, A Review of BIM Capabilities for Quantity Surveying Practice, in Proceedings of the 4th International Building Control Conference (IBCC), 7th -8th M arch 2016, Kuala L umpur, M alaysia (2016)

15. S. W u, G. Wood, K. Ginige, S.W. Jong, A technical review of BIM based cost estimating in UK quantity surveying practice, standards and tools, IT con 19, 534-562 (2014)

16. L. Ustinovičius, R. Rasiulis, L. Nazarko, T. Vilutienè, M. Reizgevicius, Innovative research projects in the field of Building L ifecycle $M$ anagement, Procedia Engineering, 122, 166-171 (2015)

17. M. Reizgevicius, L. Ustinovičius, D. Cibulskiene, V. K utut, L. N azarko, Promoting Sustainability through Investment in Building Information M odeling (BIM) Technologies: A Design Company Perspective, Sustainability 10(3), 1-22 (2018) 
18. O.A. Olatunji V iews on building information modelling, procurement and contract management, Proceedings of the Institution of Civil Engineers - M anagement, Procurement and Law 167(3), 117-126 (2014)

19. A. A shworth, K. Hogg, Willis's practice and procedure for quantity surveyor, $12^{\text {th }} \mathrm{ed}$. (Blackwell Publishing Ltd., Oxford, 2007)

20. W. Sher, S. Sheratt, A. W illiams, R. Gameson, Heading into new virtual environments: what skills do design team members need? J. Inf. Tech. Cons. 14, 17-29 (2009)

21. M. Paulk, B. Curtis, M. Chrissis, C. W eber, The Capability Maturity Model for Software (Software Engineering Institute, Carnegie M ellon University,1993)

22. P.B. Crosby, Quality is Free: The Art of Making Quality Certain (N ew A merican Library, N ew Y ork, 1979)

23. R. Eadie, S. Perera, G. Heaney, K ey Process A rea M apping in the Production of an Ecapability M aturity M odel for UK Construction Organisations, J FM PC 16(3), 197-210 (2011)

24. Succar, B. Building Information M odelling M aturity M atrix. Handbook of Research on Building Information M odeling and Construction Informatics: Concepts and Technologies, IGI, 65-103 (2010)

25. B. Succar, W. Sher, A. W illiams, M easuring BIM Performance: Five metrics. A rchitect. Eng. Des. M anag. 8(2), 120-142 (2012)

26. IU, Building Information Modeling (BIM) Guidelines and Standards for Architects, Engineers, and Contractors (Indiana University, USA, 2009)

27. N. Gu, K. London, Understanding and facilitating BIM adoption in the AEC industry, A utomat. Constr. 19(8), 988-999 (2010)

28. A.M. M ahamadu, L. M ahdjoubi, C. B ooth, Critical BIM Qualification Criteria for Construction Pre-Qualification and Selection, A rchitect. Eng. Des. M anag. 13(5), 326$343(2017 a)$

29. A. Azzouz, P. Hill, Hunting for perfection: How A rup measures BIM maturity on projects worldwide, Cons. Res. Innov. 8(2), 49-54 (2017)

30. M. Hallowell, J. Gambatese, Qualitative Research: A pplication of the Delphi M ethod to CEM Research, J. Constr. Eng. M anag. 136(1), 99-107 (2010)

31. D.E. Polkinghorne, Phenomenological research methods, in Existentialphenomenological perspectives in psychology, 41-60 (Springer, 1989)

32. J.W. Creswell, Qualitative Inquiry and Research Design: Choosing among Five Approaches, 3rd ed. (Sage Publications, London, 2013).

33. A.M. M ahamadu, P. M anu, A. Poghosyan, L. M ahdjoubi, A. Gibb, M. B ehm, Organisational attributes that determine design for occupational safety and health capability, in Submitted to CRIOCM 2017 22nd International Conference on A dvancement of Construction M anagement and Real Estate, 20-23 N ovember 2017, Swinburne University of Technology, A ustralia (2017b) 